\title{
Functional neural changes and altered cortical-subcortical connectivity associated with recovery from Internet gaming disorder
}

\author{
GUANG-HENG DONG ${ }^{1,2}$, MIN WANG ${ }^{1}$, JIALIN ZHANG ${ }^{3}$, XIAOXIA DU ${ }^{4}$ and MARC N. POTENZA ${ }^{5,6,7 *}$ \\ ${ }^{1}$ Center for Cognition and Brain Disorder, The Affiliated Hospital of Hangzhou Normal University, Hangzhou, China \\ ${ }^{2}$ Zhejiang Key Laboratory for Assessment of Cognitive Impairments, Hangzhou, China \\ ${ }^{3}$ Department of Psychology, Zhejiang Normal University, Jinhua, China \\ ${ }^{4}$ Shanghai Key Laboratory of Magnetic Resonance, East China Normal University, Shanghai, China \\ ${ }^{5}$ Department of Psychiatry, Department of Neurobiology, and Child Study Center, Yale University School of Medicine, \\ New Haven, CT, USA \\ ${ }^{6}$ The Connecticut Council on Problem Gambling, Wethersfield, CT, USA \\ ${ }^{7}$ The Connecticut Mental Health Center, New Haven, CT, USA
}

(Received: June 22, 2019; revised manuscript received: November 3, 2019; accepted: December 1, 2019)

\begin{abstract}
Background and aims: Although studies have suggested that individuals with Internet gaming disorder (IGD) may have impairments in cognitive functioning, the nature of the relationship is unclear given that the information is typically derived from cross-sectional studies. Methods: Individuals with active IGD $(n=154)$ and those individuals no longer meeting criteria $(n=29)$ after 1 year were examined longitudinally using functional magnetic resonance imaging during performance of cue-craving tasks. Subjective responses and neural correlates were contrasted at study onset and at 1 year. Results: Subjects' craving responses to gaming cues decreased significantly at 1 year relative to study onset. Decreased brain responses in the anterior cingulate cortex (ACC) and lentiform nucleus were observed at 1 year relative to onset. Significant positive correlations were observed between changes in brain activities in the lentiform nucleus and changes in self-reported cravings. Dynamic causal modeling analysis showed increased ACC-lentiform connectivity at 1 year relative to study onset. Conclusions: After recovery from IGD, individuals appear less sensitive to gaming cues. This recovery may involve increased ACC-related control over lentiform-related motivations in the control over cravings. The extent to which cortical control over subcortical motivations may be targeted in treatments for IGD should be examined further.
\end{abstract}

Keywords: Internet gaming disorder, longitudinal studies, anterior cingulate cortex, cue-craving task

\section{INTRODUCTION}

Internet gaming disorder (IGD) has been associated with significant impairments in social and personal functioning, poorly controlled craving (Kim et al., 2018), excessive time spent gaming (Dong, Zhou, \& Zhao, 2010), poor academic achievement (Hawi, Samaha, \& Griffiths, 2018), and other negative measures of health and functioning. IGD has been considered as an addictive disorder, and preliminary diagnostic criteria have been established in part based on another behavioral addiction, i.e., gambling disorder (Dowling, 2014; Petry, Rehbein, Ko, \& O’Brien, 2015). The fifth edition of the Diagnostic and Statistical Manual of Mental Disorders (DSM-5) listed IGD as a "Condition for further study" (American Psychiatric Association, 2013). In May 2018, gaming disorder was adopted for inclusion in the 11th edition of the International Classification of Diseases (ICD-11; http://www.who.int/features/qa/gaming-disorder/en/), despite debates (Aarseth et al., 2017; King \& Gaming Industry Response, 2018; Rumpf et al., 2018; Saunders et al., 2017).
During cue-craving tasks, IGD relative to control subjects have demonstrated greater attention to game-related cues (Choi et al., 2014), with prefrontal regions implicated (Ahn, Chung, \& Kim, 2015). During executive tasks, IGD relative to control subjects has shown diminished executive control (Nuyens et al., 2016), with the dorsolateral prefrontal cortex (DLPFC) and anterior cingulate cortex (ACC) implicated (Dong, Wang, Du, \& Potenza, 2017, 2018; Dong, Wang, Wang, Du, \& Potenza, 2019). During decision-making in IGD (Pawlikowski \& Brand, 2011), the striatum and ACC have been implicated (Qi et al., 2016). In these and other studies,

\footnotetext{
* Corresponding authors: Guang-Heng Dong, PhD; Center for Cognition and Brain Disorders, The Affiliated Hospital of Hangzhou Normal University, 2318 Yuhangtang Road, Hangzhou, Zhejiang Province 311121, China; Phone: +86 1586794 9909; Fax: +86 5712886 7717; E-mail: dongguangheng@hznu.edu.cn; Marc N. Potenza, PhD, MD; Department of Psychiatry, Yale University School of Medicine, 1 Church Street, New Haven 06511, CT, USA; Phone: +1 203737 3553; Fax: +1 203737 3591; E-mail: marc.potenza@yale.edu
}

This is an open-access article distributed under the terms of the Creative Commons Attribution-NonCommercial 4.0 International License, which permits unrestricted use, distribution, and reproduction in any medium for non-commercial purposes, provided the original author and source are credited, a link to the CC License is provided, and changes - if any - are indicated. 
cross-sectional approaches comparing IGD and control groups have typically been employed, limiting an understanding of how changes in brain function may underlie transitions in IGD.

While cross-sectional studies may reveal brain features associated with IGD, they cannot distinguish whether brain alterations may precede the development of IGD, result from the gaming behaviors or be generated by other mechanisms. As such, longitudinal studies may help disentangle neural vulnerabilities from neural consequences. Additionally, and importantly from a clinical perspective, understanding brain changes related to recovery is important, and this may be achieved through longitudinal studies.

In behavioral addictions like gambling disorder, many individuals recover naturally (i.e., without formal intervention (Slutske, 2006; Slutske, Piasecki, Blaszczynski, \& Martin, 2010). Like those with gambling disorder, many IGD individuals may recover without professional intervention (Lau, Wu, Gross, Cheng, \& Lau, 2017). Estimates of remission range from $36.7 \%$ to $51.4 \%$ in IGD (Chang, Chiu, Lee, Chen, \& Miao, 2014; Ko et al., 2014). Although potential factors (such as decreases in craving) for remission in IGD have been proposed (Chang et al., 2014; Ko et al., 2014, 2015), little is known regarding brain mechanisms underlying recovery processes in IGD.

In the current study, we investigated longitudinally a group of individuals with IGD. We used functional magnetic resonance imaging (fMRI) to scan IGD subjects at "baseline" and again after 1 year, with a focus on individuals who no longer met criteria for IGD. By comparing subjective and imaging data from individuals with active versus recovered IGD, we aimed to identify subjective and neural factors underlying recovery. This approach may provide insight into individual differences relating to resiliency and recovery and could potentially help with the development of more targeted and effective interventions.

\section{Cue reactivity and craving in $I G D$}

Craving to addiction-related cues reflects a strong motivation to engage in addictive behaviors. Craving may promote drug use (Sayette, 2016; Sinha \& Li, 2007), gambling (Potenza et al., 2003), and gaming (Dong et al., 2017) in individuals with related disorders. Thus, craving has been a target of therapies for addictions (Potenza et al., 2013), as craving may shift attention toward addiction-related cues (Sayette, 2016; Tiffany, 1990), influence the evaluation of relevant information (Sayette, Schooler, \& Reichle, 2010), and impair decisionmaking processes (Balodis \& Potenza, 2015; Berridge \& Kringelbach, 2015; Dong \& Potenza, 2016). In addition, reexposure to drug-related cues may lead to strong cravings and drug-seeking behaviors in drug addictions (Gardner, McMillan, Raynor, Woolf, \& Knapp, 2011). For the aforementioned reasons (including IGD's classification as an addictive disorder), we focused on craving in this study of IGD.

Like drug cues in drug addictions, gaming cues may trigger game-seeking behaviors in IGD (Dong \& Potenza, 2016). IGD participants have exhibited higher cue-induced brain features in the ventral and dorsal striatum (Liu et al., 2017), altered functional networks (Ko et al., 2013; Ma et al., 2019), higher late positive potential amplitude
(Kim et al., 2018), when compared with control subjects when exposed to gaming cues. Neural responses to gaming cues may predict the emergence of IGD (Dong, Wang, Liu, et al., 2019) and operate in a gender-sensitive fashion (Dong, Wang, et al., 2018). Thus, we hypothesized that brain regions implicated in prior studies of craving (e.g., the striatum) would show less activation following recovery than during active IGD when subjects were exposed to gaming cues.

When individuals are exposed to gaming-related cues, cortical brain regions (e.g., the DLPFC and ACC) may exert control over subcortical brain regions (e.g., the striatum) in addictions such as in tobacco-smoking (Kober et al., 2010) and models of cognitive control generally (Bush, Luu, \& Posner, 2000). Executive functions involve a set of processes necessary for cognitive control, including selection and monitoring of behaviors to facilitate achievement of chosen goals (Hall et al., 2017). Addictions have been associated with impaired inhibitory control (Dalley, Everitt, \& Robbins, 2011; Ersche et al., 2012), and these findings extend to behavioral addictions (Leeman \& Potenza, 2012; Yip et al., 2018). Diminished cognitive control over craving may underlie engagement in addictive behaviors (Wang, Wu, Wang, et al., 2017; Wang, Wu, Zhou, et al., 2017). Theoretical models, such as the I-PACE (Brand et al., 2016) and others (Dong \& Potenza, 2014), propose that a failure in executive control may underlie problematic gaming behaviors. Studies of IGD have found hypoactivity of the brain regions involving in executive control (Nuyens et al., 2016), including the DLPFC and dorsal ACC (Dong \& Potenza, 2014). Better executive control may help in controlling cravings effectively, a goal of interventions like cognitive behavioral therapy that has been applied to addictions and Internet-use behaviors like gaming (Young \& Brand, 2017). We hypothesized that activation of regions implicated in executive control (DLPFC and ACC) would show greater activation following recovery as compared to during active IGD.

Given that prior studies have demonstrated DLPFC control over striatal activation in cue-elicited craving (Kober et al., 2010), we further hypothesized that changes in cortical activation would relate to control over brain activities in reward-related brain regions like the striatum. Dynamic causal modeling, an analytic approach that can be used to investigate and quantify directed influences of neuronal populations (He et al., 2019), is well suited to examine how executive regions may exert control over subcortical processes. With respect to subjective responses, we hypothesized that neural activations would relate to subjective reports of craving that we anticipated would be less strong following recovery than during active IGD.

\section{METHODS}

\section{Overview of the procedure}

From 2016 to 2017, we recruited 154 IGD subjects for fMRI during a cue-craving task (described below). We contacted participants after approximately 1 year and reevaluated them for IGD. Twenty-nine IGD subjects (five females) who did not satisfy the criteria of IGD anymore agreed to participate during scanning when performing the cue-craving task. We then 


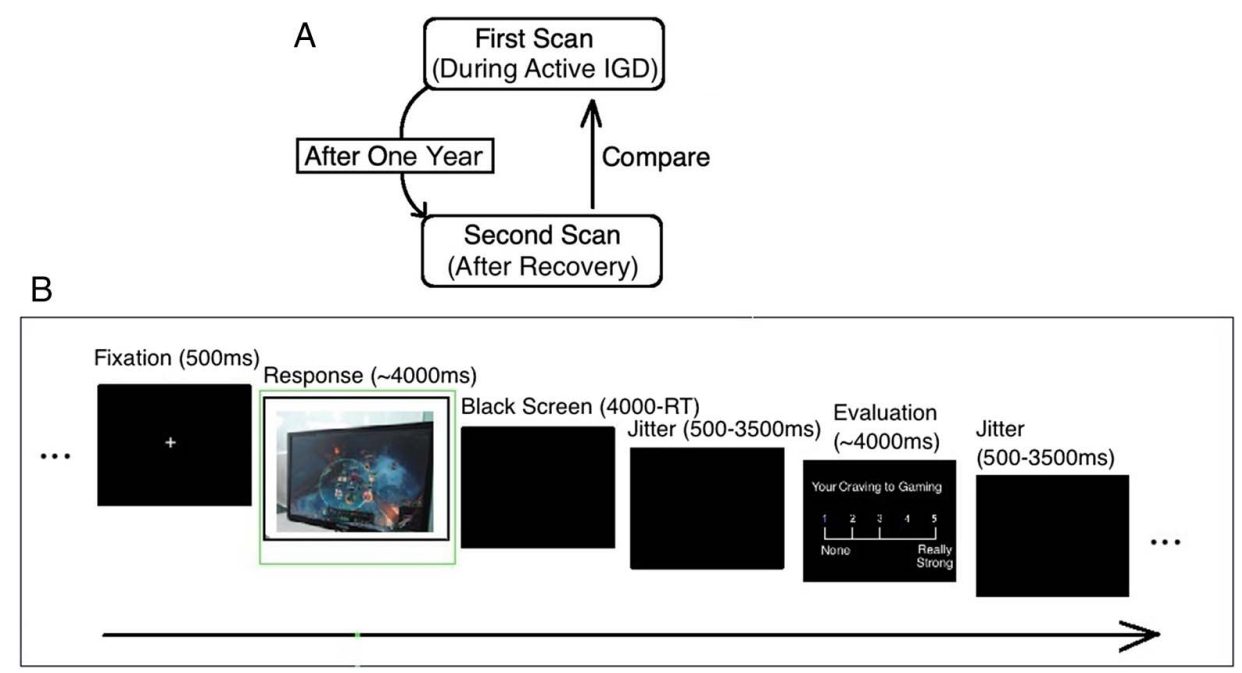

Figure 1. Study design and the task used in this study. (A) The design of the 1-year tracking study. (B) The timeline of one trial in this study

compare their more recent data (recovered IGD) to the baseline data (active IGD) to identify differences over time (Figure 1A).

\section{Subject selection}

At study onset, participants were classified as having IGD if they scored 50 or higher on Young's Internet Addiction Test (a self-report questionnaire) and met at least five DSM-5 criteria for IGD (clinical interview; see "Supplemental Material" for additional details; Petry et al., 2014; Young, 2009). All participants underwent structured psychiatric interviews (MINI) conducted by an experienced psychiatrist (Lecrubier et al., 1997), and individuals with psychiatric disorders or behaviors were excluded (see "Supplemental Material"). In addition, no subjects reported previous experience with gambling or illicit drugs (e.g., cannabis and heroin). All subjects played League of Legends (LOL and Riot Games) for more than 1 year. This criterion was based on our use of gaming cues as stimuli in this study and LOL being the most popular online game during study onset. Individuals who recovered from IGD were needed to score less than 50 on Young's Internet Addiction Test and meet less than five DSM-5 criteria for IGD at the 1-year time (Petry et al., 2014; Young, 2009; see Table 1 for details).

\section{Task}

An event-related cue-reactivity task was used in this study, as has been described previously (Dong et al., 2017; Dong, Wang, et al., 2018). The task contains two types of cue pictures: 30 gaming-related pictures and 30 typing-related pictures (neutral baseline). Within each type, half of the 30 pictures contained a face and hands and half contained only hands. Gaming-related pictures show a person who is playing the online game (LOL) on a computer. In typingrelated pictures, the same person is typing an article on a keyboard in front of a computer. Participants were instructed to indicate whether or not there was a face in the picture by pressing the button " 1 " on the keyboard when a face was present and pressing " 2 " when there was no face present.

Figure 1B shows the timeline of a sample trial in the task. First, a fixed $500 \mathrm{~ms}$ of cross was presented, followed by a cue picture as described above. Pictures were presented in a randomized order to avoid order effects. Each picture was presented for up to $3,000 \mathrm{~ms}$, during which time participants needed to respond. The screen turned to black after buttonpressing and lasted for 3,000 (response time) ms. Then, in the craving evaluation stage, participants were asked to evaluate the level of their craving for the corresponding stimuli on a 5 -point scale, ranging 1 (no craving) to 5 (extremely high craving). This stage lasted for up to $3,000 \mathrm{~ms}$ and was terminated by a button press. Finally, a $1,500-3,500 \mathrm{~ms}$ blank screen was presented between each trial. The whole task contained 60 trials and lasted approximately $9 \mathrm{~min}$. The task was presented and behavioral data were collected using Eprime software (Psychology Software Tools, Inc., Sharpsburg, PA, USA). All participants were asked to complete a 10-item gaming urge questionnaire, with scores ranging from 1 to 10 , to assess gaming-related craving prior to fMRI (Cox, Tiffany, \& Christen, 2001).

Table 1. Demographic features of IGD participants when IGD was active and recovered

\begin{tabular}{lcrrr}
\hline & Active & Recovered & $t$ & \multicolumn{1}{c}{$t$} \\
\hline Age (years; mean $\pm S D$ ) & $21.46 \pm 1.83$ & $21.73 \pm 1.91$ & 0.823 & $>.050$ \\
IAT score (mean $\pm S D$ ) & $65.21 \pm 11.56$ & $34.45 \pm 4.10$ & 18.86 & $<.001$ \\
DSM-5 IGD score (mean $\pm S D$ ) & $5.76 \pm 0.91$ & $2.83 \pm 0.66$ & 15.82 & $<.001$ \\
Self-reported craving $($ mean $\pm S D)$ & $53.07 \pm 15.47$ & $30.34 \pm 6.44$ & 9.19 & $<.001$ \\
\hline
\end{tabular}

Note. IAT: Internet Addiction Test; DSM: Diagnostic and Statistical Manual of Mental Disorders; IGD: Internet gaming disorder; $S D$ : standard deviation. 


\section{Data analysis}

Preprocessing of the fMRI data was conducted using SPM12 (http://www.fil.ion.ucl.ac.uk/spm) and Neuroelf (http://neuroelf.net), as described previously (Dong et al., 2017; Dong, Wang, et al., 2018). Images were slice-timed, reoriented, and realigned to the first volume, with T1-coregistered volumes used to correct for head movements. Images were then normalized to MNI space and spatially smoothed using a $6-\mathrm{mm}$ full width at half maximum Gaussian kernel. No subjects were removed from analysis because of head motion (the exclusion criteria were $2 \mathrm{~mm}$ in directional movement or $2^{\circ}$ in rotational movement). A general linear model (GLM) was applied to identify BOLD activation in relation to brain activities. Different types of trials (gaming-related, typing-related, incorrect, or missed) were separately convolved with a canonical hemodynamic response function to form task regressors. The duration of each trial was $4,000 \mathrm{~ms}$. The GLMs included a constant term per run. Six head-movement parameters derived from the realignment stage and gaming history (self-reported years of gaming) were included to address these potential confounds. A GLM approach was used to identify voxels that were significantly activated for each event during the "response" stage.

The second-level analyses were conducted as follows. First, a voxel-wise repeated-measures analysis throughout the whole brain was conducted to investigate activity related to $\left[\left(\right.\right.$ recovered $_{\text {Gaming-related stimuli }}-$ recovered $\left._{\text {Typing-related stimuli }}\right)-$ (active $_{\text {gaming-related stimuli }}-$ active $_{\text {Typing-related stimuli }}$ )]. Familywise error thresholds $(p<.001)$ were determined using $3 \mathrm{dClustSim}$ (an updated version of Alphasim), and all comparisons were corrected using 3dClustSim (https://afni. nimh.nih.gov/pub/dist/doc/program_help/3dClustSim.html), $p<.001$, two-tailed, with an extent of at least 40 voxels.

\section{Ethics}

This experiment was approved by the Human Investigations Committee of Zhejiang Normal University and conformed to The Code of Ethics of the World Medical Association (Declaration of Helsinki). All participants provided written informed consent before scanning.

\section{RESULTS}

Recovered versus active IGD subjects showed decreased brain activations in bilateral ACC, bilateral medial frontal gyrus (MFG), left lentiform, right insula, left superior temporal gyrus, and left cuneus (Figure 2A; Table 2). Beta-weight measures showed that these differences were related to decreased brain responses following recovery (Figure 2B, C).

\section{Correlations}

We analyzed the correlations between the brain responses in the left ACC and lentiform and self-reported craving to cues.
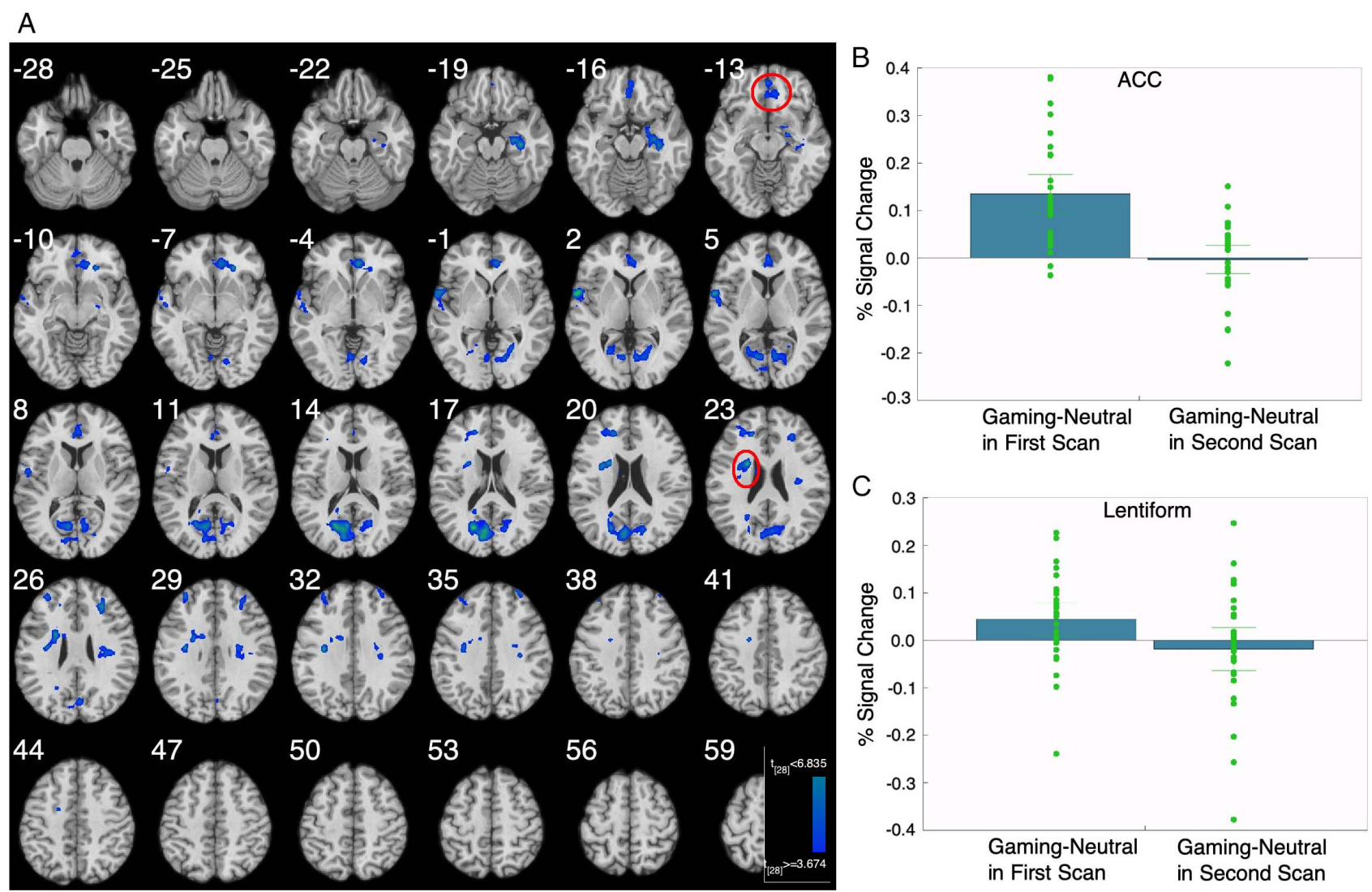

Figure 2. Imaging results when comparing IGD subjects in recovery and when gaming problematically. (A) Brain regions surviving after comparison between when subjects are in recovery versus actively gaming problematically. (B, C) Beta weights extracted from the ACC and lentiform regions of interest when subjects were actively gaming problematically and in recovery 
Dong et al.

Table 2. Comparison of brain responses of subjects with active IGD and recovered IGD

\begin{tabular}{lccclc}
\hline Cluster number & $x, y, z^{\mathrm{a}}$ & Peak intensity & Cluster size $^{\mathrm{b}}$ & \multicolumn{1}{c}{ Region $^{\mathrm{c}}$} & Brodmann's area $^{\text {(n) }}$ \\
\hline 1 & $-6,36,-3$ & -5.240 & 85 & Left anterior cingulate & 12 \\
2 & $0,39,6$ & -4.577 & 54 & Right anterior cingulate & 32 \\
3 & $-18,-21,-18$ & -5.183 & 63 & Left medial frontal gyrus & 46 \\
4 & $27,36,24$ & -5.164 & 41 & Right middle frontal gyrus & 46 \\
5 & $-21,3,21$ & -5.821 & 107 & Left lentiform & 18 \\
6 & $30,-12,27$ & -4.740 & 44 & Right insula & 22 \\
7 & $-18,36,24$ & -6.075 & 436 & Left cuneus & \\
8 & $-60,3,3$ & -6.106 & 83 & Left superior temporal gyrus & \\
\hline
\end{tabular}

Note. IGD: Internet gaming disorder.

${ }^{\mathrm{a}}$ Peak MNI coordinates. ${ }^{\mathrm{b}}$ Number of voxels. $p<.001$, cluster size $>40$ contiguous voxels. Voxel size $=3 \times 3 \times 3$. ${ }^{\mathrm{c}}$ The brain regions were referenced to the software Xjview (http://www.alivelearn.net/xjview8) and verified through comparisons with a brain atlas.

Significant correlations between self-reported cravings and lentiform activations were found, regardless of IGD status (Figure 3). No significant correlations were observed between ACC activations and cravings.

\section{Effective ACC-lentiform connectivity in IGD subjects}

We further analyzed the effective connectivity between the left ACC and left lentiform using dynamic causal modeling (DCM) at the two timepoints. The nodes used were defined through the interaction results presented above. Of the several brain regions identified in the whole-brain analyses, the ACC is located in the executive-control network and the lentiform nucleus in the reward network. Given our hypothesis that executive control over craving should be changed in recovery from IGD, we selected these two brain regions as regions of interests in this study for connectivity analyses. In other words, we selected these two regions as components of executive-control and reward networks to investigate interactions between these two systems in recovery from IGD.

We took the coordinate of the peak of the clusters (local maxima in the statistical map) as the central point to create spheres with 6-mm radii [left lentiform $(-21,3,21)$; ACC $(-3,39,6)]$. About 33 voxels were included in each sphere. These regions identified for each group were included in a dynamic network, and DCM was used to determine the network's most likely structure, given the data.

In fixed connectivity, DCM estimates demonstrated significantly increased ACC-lentiform connectivity when IGD subjects recovered $(t=3.167, p=.003)$. Similarly, lentiform-ACC connectivity was also significantly increased when IGD subjects recovered $(t=4.399, p<.001)$.

Similar features were also observed when subjects were exposed to gaming cues. In modulating effects, DCM estimates demonstrated significantly increased ACClentiform connectivity when IGD subjects recovered $(t=2.769, p=.009)$. However, lentiform-ACC connectivity was only marginally increased when IGD subjects recovered $(t=1.798, p=.09$; Figure 4$)$.

\section{DISCUSSION}

This study investigated neural features of cue reactivity in IGD subjects longitudinally to identify neural factors associated with recovery. Decreased brain responses to gaming cues in the lentiform nucleus and ACC were associated with recovery. Better effective ACC-lentiform connectivities were also observed in IGD subjects following recovery. The findings suggest that interactions between reward and executive control systems may be important in IGD.

\section{Decreased sensitivity to gaming cues}

Consistent with our hypothesis, decreased gaming cuerelated activations in reward circuit-related brain regions [lentiform, ventromedial prefrontal cortex (vmPFC, including orbitofrontal cortex (OFC)] were found when IGD subjects recovered from gaming. Reward circuitry may influence motivated or goal-directed behaviors and reward processing (Ikemoto, Yang, \& Tan, 2015; Sayette, 2016), including in addictions (Balodis \& Potenza, 2015; Cheng et al., 2016; Tobler et al., 2016; Yang et al., 2017). The reward system could be activated when individuals are exposed to relevant stimuli in substance use or gambling disorders (Balodis et al., 2012; Worhunsky, Malison, Rogers, \& Potenza, 2014) as well as in IGD (Ko et al., 2009; Liu et al., 2017; Sun et al., 2012). Individuals with IGD as compared to those with regular game use have shown higher lentiform activation to gaming cues, consistent with cue reactivity and craving findings in substance use disorders (Dong et al., 2017; Dong, Wang, et al., 2018).

In this study, decreased activations were found in the lentiform nucleus and other reward-related brain regions after recovery. The findings suggest that neural response to gaming cues decreases following recovery, which is consistent with previous studies comparing IGD with controls (Kim et al., 2018; Ko et al., 2013; Ma et al., 2019). The correlations between decreases in lentiform activation and self-reported cue-elicited craving provide support to the notion that decreased neural reactivity in the lentiform may underlie decreased cue-elicited craving responses in recovery in IGD and may relate importantly to diminished motivations to engage excessively in gaming behaviors. Our previous study showed that gaming behaviors could increase IGD subjects' craving (Dong, Wang, et al., 2018). Furthermore, we previously reported that greater lentiform activation to gaming cues was linked to emergence of IGD in individuals with regular game use (Dong, Wang, Liu, et al., 2019). This study suggests that during recovery a decrease in problematic gaming is linked to decreased cravings in IGD, with the lentiform nucleus implicated in 
A

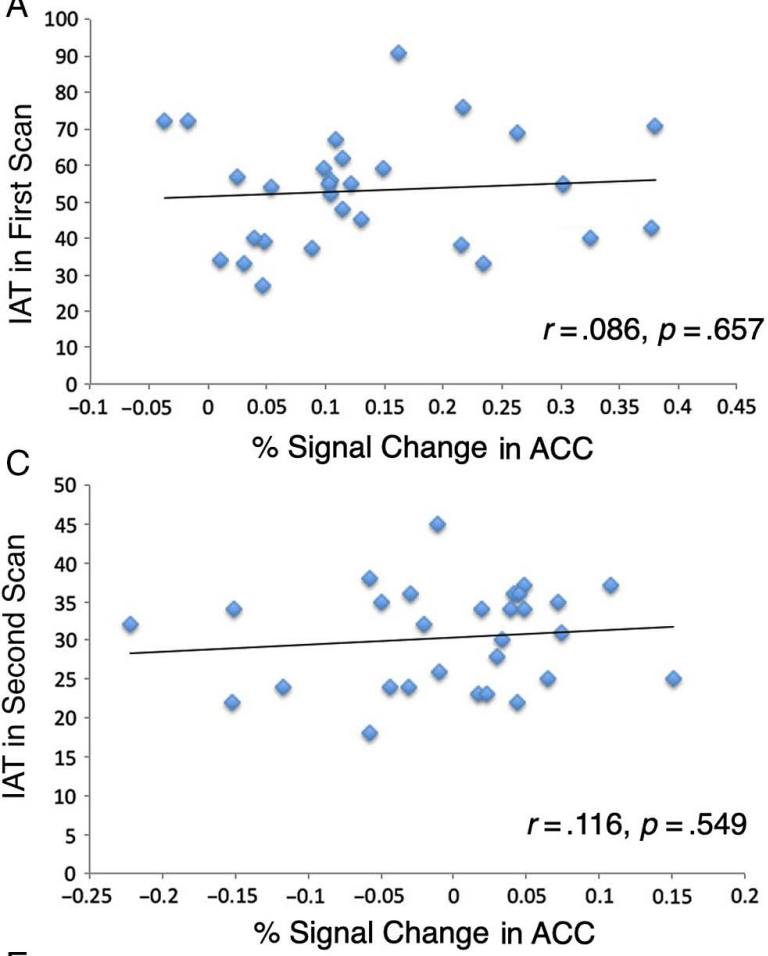

$\mathrm{E}$

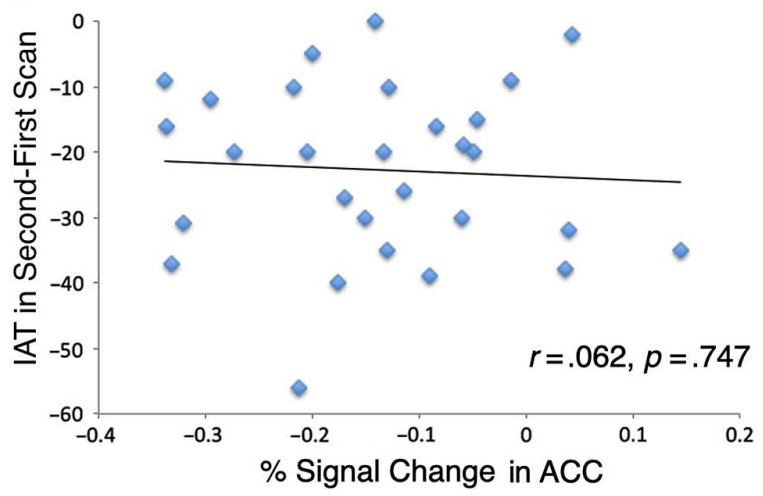

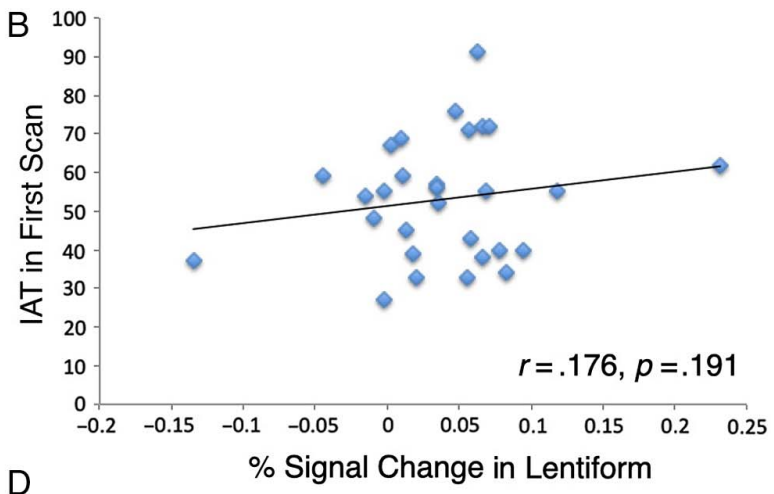

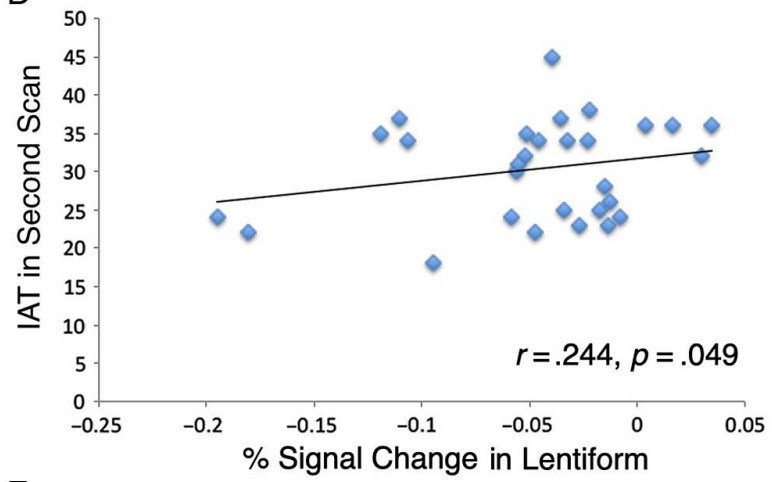

$\mathrm{F}$

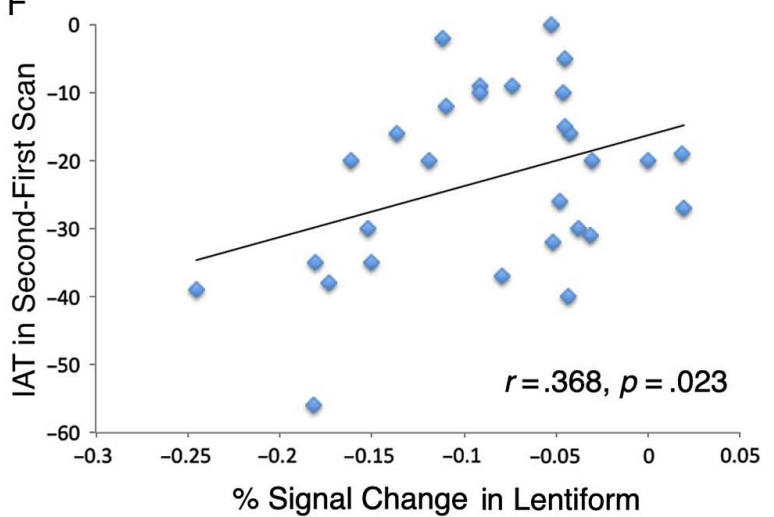

Figure 3. (A, B) Correlations between brain ACC and lentiform activity and subjective craving when gaming in the first scan. (C, D) Correlations between brain ACC and lentiform activity and subjective craving when gaming in the second scan. (E, F) Correlations between brain ACC and lentiform activity and subjective craving when gaming in the second-first scan

this relationship. Taken together, the findings suggest an important role for the lentiform nucleus and cue-elicited craving in transitions between IGD and regular game use and vice versa. The precise relationships (e.g., whether decreased gaming leads to decreased lentiform responsivity and decreased craving or whether decreased lentiform responsivity leads to decreased craving and decreased gaming) require further investigation.

\section{Control of craving after recovery}

Another brain region showing group differences was the ACC, which has been implicated in executive control and other processes. In contrast to our hypothesis, activation was decreased in the ACC (as well as in the MFG) after recovery. The cluster identified included the ACC and MFG and extended ventrally to include the vmPFC and OFC. Notably, the medial prefrontal cortex has been implicated in cue-elicited craving in substance addictions like cocaine-use disorder (Kober et al., 2016; Wexler et al., 2001), processing of rewards, especially during notification or outcome phases (Knutson, Fong, Adams, Varner, \& Hommer, 2001; Knutson \& Greer, 2008), decision-making (Tanabe et al., 2007), default-mode processing (Harrison et al., 2017), and other processes (Li, Mai, \& Liu, 2014). Given that the task employed in this study focused on cue-elicited craving, it is tempting to speculate that the relatively decreased activation observed in the cluster involving the OFC/vmPFC/ACC/ MFG may relate to diminished cue reactivity, although this interpretation is less supported by data than the lentiform findings given the absence of a correlation with self-reported cravings.

Given that the ACC and other cortical brain regions have been implicated in executive or cognitive control (Rolls, 2000), including in people with addictive disorders (Filbey et al., 2008; Franklin et al., 2007; Kosten et al., 2005; Myrick et al., 2004; Wrase et al., 2002), it is possible that individuals with IGD who have recovered are demonstrating 
A

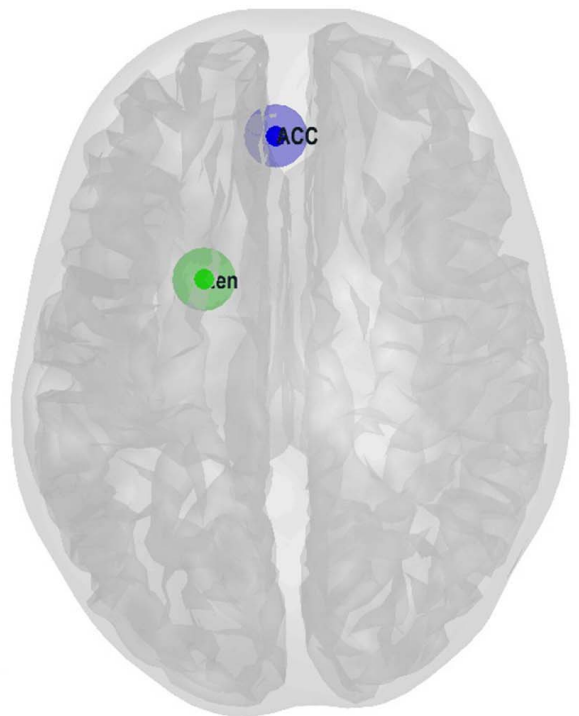

B $\quad$ Fixed Effect

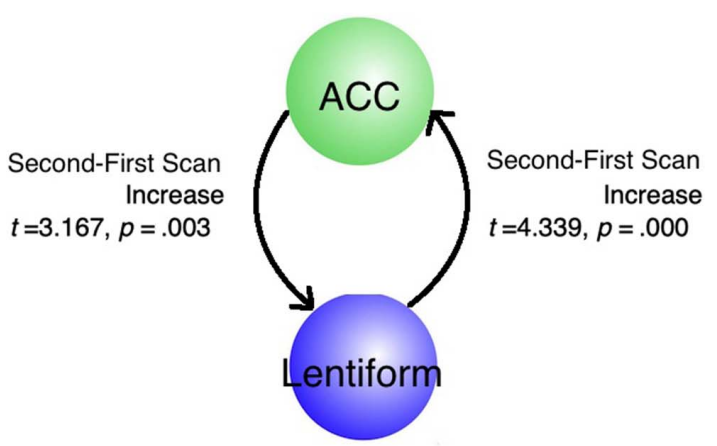

C

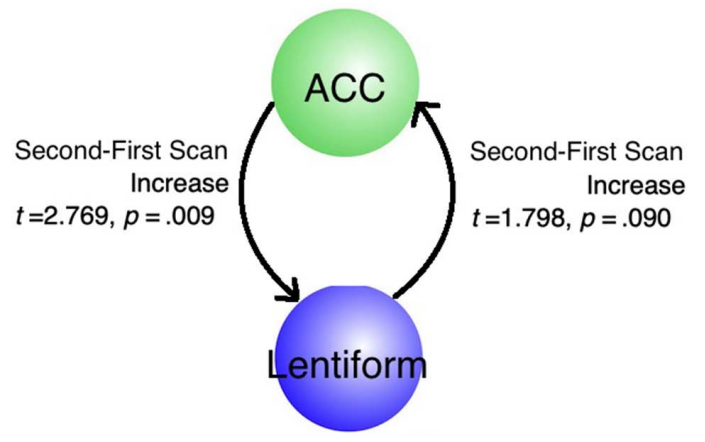

Figure 4. DCM results in IGD subjects when actively gaming problematically and during recovery. (A) The nodes that were selected for further analysis. (B) Changes in the fixed effects between the ACC and lentiform regions of interest at different time points. (C) Changes in the modulatory effects between the ACC and lentiform regions of interest at different time points

more efficient processing of control regions relative to when they were gaming problematically. To examine relationships between ACC and lentiform activities, we applied DCM and found that the connectivities were increased following recovery. According to psychophysiological interpretations of functional connectivities among these brain regions (Havlicek et al., 2015; Stephan et al., 2010), higher values in ACC-lentiform and lentiform-ACC connectivities during recovery relative to times when gaming problematically suggest that the interactions among these two brain regions are more efficient in subjects following recovery. As such, future research should examine the extent to which this reflects a mechanism for controlling cravings more efficiently, concurrent coupling of regions involved in reward processing, or craving-related motivations or other possibilities.

\section{Importance and clinical implications}

Theoretical models have proposed important roles for cortical and subcortical brain regions in Internet-use behaviors and disorders. A recent update of the I-PACE model (Brand et al., 2019) proposed behavioral and neural mechanisms related to transitions in Internet-use disorders like IGD. In this model, cue reactivity and changes in cortical-to-basalganglia circuitries were important components, consistent with the findings in this study. Of note, the updated I-PACE model also proposes a role for the insula (Brand et al., 2019), consistent with changes in cue-reactivity and craving findings and insular activation and connectivity in individuals with IGD receiving a craving-behavioral intervention (Zhang et al., 2016b). Furthermore, resting-state data from the same cohort suggested decreased connectivity (e.g., between the OFC and hippocampus and between the posterior cingulate and motor-related regions; Zhang et al., 2016a). As such, this study and other recent ones suggest potential neural targets for interventions (e.g., using brain modulation methods like rapid transcranial magnetic stimulation or transcranial direct current stimulation) to reduce cravings and promote recovery in IGD. Behavioral approaches that target craving and might operate through shared or distinct neural mechanisms (e.g., cognitivebehavioral and mindfulness-based therapies) should also be considered in light of the current findings, especially given the important role for behavioral therapies in the treatment of addictions and the value of understanding how specific therapies may operate at neurobiological levels.

\section{Limitations}

Several limitations should be mentioned. First, we did not include healthy control subjects in this study. Although we have found that gaming history was not related to IGD severity $(r=.088, p=.494)$ and also included gaming history as a factor in the GLM, a control group may have been helpful in understanding the data (e.g., with respect to possible test-retest effects). Second, most study subjects were male (only five females). As such, future studies should examine the extent to which the findings may apply to female populations, especially as gender-related differences have been observed in neural correlates in IGD populations (Dong, Wang, et al., 2018; Dong, Wang, Wang, et al., 2019; Dong, Zheng, et al., 2018). Third, although we performed a DCM analysis that suggests that executive control over lentiform activation may improve with recovery, we cannot exclude other possible explanations that should be investigated directly in future studies. 


\section{CONCLUSIONS}

IGD subjects in recovery show decreased craving responses to gaming cues at subjective and neural levels. Future research should directly examine the extent to which the findings represent cortical control over subcortical processes in craving responses versus other possibilities, and should examine how interventions targeting cortical-subcortical interactions may be effective in the treatment of IGD.

Funding sources: This research was supported by National Science Foundation of China (31371023). Dr. MNP's involvement was supported by the National Center for Responsible Gaming, the Connecticut Council on Problem Gambling, and the Connecticut Department of Mental Health and Addiction Services. The funding agencies did not contribute to the experimental design or conclusions, and the views presented in the manuscript are those of the authors and may not reflect those of the funding agencies.

Authors' contribution: GD designed the task and wrote the first draft of the manuscript. MW and JZ collected and analyzed the data and prepared the figures and tables. XD contributed in collecting and preparing the data. MNP contributed in editing, interpretation, and revision processes. All authors contributed to and have approved the final version of the manuscript.

Conflict of interest: The authors report no financial conflicts of interest with respect to the content of this manuscript. Dr. MNP has received financial compensation for consulting and advising to RiverMend Health, Opiant/Lightlake Therapeutics, and Jazz Pharmaceuticals; has received unrestricted research support (to Yale) from Mohegan Sun Casino and grant support (to Yale) from the National Center for Responsible Gaming; and has consulted or advised legal and gambling entities on issues related to addictions and impulse control disorders.

\section{REFERENCES}

Aarseth, E., Bean, A. M., Boonen, H., Colder Carras, M., Coulson, M., Das, D., Deleuze, J., Dunkels, E., Edman, J., Ferguson, C. J., Haagsma, M. C., Helmersson Bergmark, K., Hussain, Z., Jansz, J., Kardefelt-Winther, D., Kutner, L., Markey, P., Nielsen, R. K. L., Prause, N., Przybylski, A., Quandt, T., Schimmenti, A., Starcevic, V., Stutman, G., Van Looy, J., \& Van Rooij, A. J. (2017). Scholars' open debate paper on the World Health Organization ICD-11 Gaming Disorder proposal. Journal of Behavioral Addictions, 6(3), 267-270. doi:10.1556/2006.5.2016.088

Ahn, H. M., Chung, H. J., \& Kim, S. H. (2015). Altered brain reactivity to game cues after gaming experience. Cyberpsychology Behavior, and Social Networking, 18(8), 474-479. doi:10.1089/cyber.2015.0185

American Psychiatric Association. (2013). Diagnostic and statistical manual of mental disorders (5th ed.). Washington, DC: American Psychiatric Association.
Balodis, I. M., Kober, H., Worhunsky, P. D., Stevens, M. C., Pearlson, G. D., \& Potenza, M. N. (2012). Attending to striatal ups and downs in addictions. Biological Psychiatry, 72(10), e25-e26. doi:10.1016/j.biopsych.2012.06.016

Balodis, I. M., \& Potenza, M. N. (2015). Anticipatory reward processing in addicted populations: A focus on the monetary incentive delay task. Biological Psychiatry, 77(5), 434-444. doi:10.1016/j.biopsych.2014.08.020

Berridge, K. C., \& Kringelbach, M. L. (2015). Pleasure systems in the brain. Neuron, 86(3), 646-664. doi:10.1016/j.neuron.2015. 02.018

Brand, M., Wegmann, E., Stark, R., Muller, A., Wolfling, K., Robbins, T. W., \& Potenza, M. N. (2019). The Interaction of Person-Affect-Cognition-Execution (I-PACE) model for addictive behaviors: Update, generalization to addictive behaviors beyond Internet-use disorders, and specification of the process character of addictive behaviors. Neuroscience and Biobehavioral Reviews, 104, 1-10. doi:10.1016/j.neubiorev. 2019.06.032

Brand, M., Young, K. S., Laier, C., Wölfling, K., \& Potenza, M. N. (2016). Integrating psychological and neurobiological considerations regarding the development and maintenance of specific Internet-use disorders: An Interaction of PersonAffect-Cognition-Execution (I-PACE) model. Neuroscience and Biobehavioral Reviews, 71, 252-266. doi:10.1016/j. neubiorev.2016.08.033

Bush, G., Luu, P., \& Posner, M. I. (2000). Cognitive and emotional influences in anterior cingulate cortex. Trends in Cognitive Sciences, 4(6), 215-222. doi:10.1016/S1364-6613(00)01483-2

Chang, F. C., Chiu, C. H., Lee, C. M., Chen, P. H., \& Miao, N. F. (2014). Predictors of the initiation and persistence of Internet addiction among adolescents in Taiwan. Addictive Behaviors, 39(10), 1434-1440. doi:10.1016/j.addbeh.2014.05.010

Cheng, Y., Huang, C. C., Ma, T., Wei, X., Wang, X., Lu, J., \& Wang, J. (2016). Distinct synaptic strengthening of the striatal direct and indirect pathways drives alcohol consumption. Biological Psychiatry, 81(11), 918-929. doi:10.1016/ j.biopsych.2016.05.016

Choi, J. S., Park, S. M., Roh, M. S., Lee, J. Y., Park, C. B., Hwang, J. Y., Gwak, A. R., \& Jung, H. Y. (2014). Dysfunctional inhibitory control and impulsivity in Internet addiction. Psychiatry Research, 215(2), 424-428. doi:10.1016/j.psychres. 2013.12.001

Cox, L. S., Tiffany, S. T., \& Christen, A. G. (2001). Evaluation of the Brief Questionnaire of Smoking Urges (QSU-brief) in laboratory and clinical settings. Nicotine \& Tobacco Research, 3(1), 7-16. doi:10.1080/14622200020032051

Dalley, J. W., Everitt, B. J., \& Robbins, T. W. (2011). Impulsivity, compulsivity, and top-down cognitive control. Neuron, 69(4), 680-694. doi:10.1016/j.neuron.2011.01.020

Dong, G., \& Potenza, M. N. (2014). A cognitive-behavioral model of Internet gaming disorder: Theoretical underpinnings and clinical implications. Journal of Psychiatric Research, 58, 7-11. doi:10.1016/j.jpsychires.2014.07.005

Dong, G., \& Potenza, M. N. (2016). Risk-taking and risky decision-making in Internet gaming disorder: Implications regarding online gaming in the setting of negative consequences. Journal of Psychiatric Research, 73, 1-8. doi:10.1016/j.jpsychires.2015.11.011

Dong, G., Wang, L., Du, X., \& Potenza, M. N. (2017). Gaming increases craving to gaming-related stimuli in individuals 
with Internet gaming disorder. Biological Psychiatry: Cognitive Neuroscience and Neuroimaging, 2(5), 404-412. doi:10.1016/j.bpsc.2017.01.002

Dong, G., Wang, L., Du, X., \& Potenza, M. N. (2018). Genderrelated differences in neural responses to gaming cues before and after gaming: Implications for gender-specific vulnerabilities to Internet gaming disorder. Social Cognitive and Affective Neuroscience, 13(11), 1203-1214. doi:10.1093/scan/nsy084

Dong, G., Wang, M., Liu, X., Liang, Q., Du, X., \& Potenza, M. N. (2020). Cue-elicited craving-related lentiform activation during gaming deprivation is associated with the emergence of Internet gaming disorder. Addiction Biology, 25(1), e12713. doi: $10.1111 / \mathrm{adb} .12713$

Dong, G., Wang, Z., Wang, Y., Du, X., \& Potenza, M. N. (2019). Gender-related functional connectivity and craving during gaming and immediate abstinence during a mandatory break: Implications for development and progression of Internet gaming disorder. Progress in Neuro-Psychopharmacology \& Biological Psychiatry, 88, 1-10. doi:10.1016/j.pnpbp.2018.04.009

Dong, G., Zheng, H., Liu, X., Wang, Y., Du, X., \& Potenza, M. N. (2018). Gender-related differences in cue-elicited cravings in Internet gaming disorder: The effects of deprivation. Journal of Behavioral Addictions, 7(4), 953-964. doi:10.1556/2006.7. 2018.118

Dong, G., Zhou, H., \& Zhao, X. (2010). Impulse inhibition in people with Internet addiction disorder: Electrophysiological evidence from a Go/NoGo study. Neuroscience Letters, 485(2), 138-142. doi:10.1016/j.neulet.2010.09.002

Dowling, N. A. (2014). Issues raised by the DSM-5 Internet gaming disorder classification and proposed diagnostic criteria. Addiction, 109(9), 1408-1409. doi:10.1111/add.12554

Ersche, K. D., Turton, A. J., Chamberlain, S. R., Muller, U., Bullmore, E. T., \& Robbins, T. W. (2012). Cognitive dysfunction and anxious-impulsive personality traits are endophenotypes for drug dependence. American Journal of Psychiatry, 169(9), 926-936. doi:10.1176/appi.ajp.2012.11091421

Filbey, F. M., Claus, E., Audette, A. R., Niculescu, M., Banich, M. T., Tanabe, J., Du, Y. P., \& Hutchison, K. E. (2008). Exposure to the taste of alcohol elicits activation of the mesocorticolimbic neurocircuitry. Neuropsychopharmacology, 33(6), 1391-1401. doi:10.1038/sj.npp.1301513

Franklin, T. R., Wang, Z., Wang, J., Sciortino, N., Harper, D., Li, Y., Ehrman, R., Kampman, K., O’Brien, C. P., Detre, J. A., \& Childress, A. R. (2007). Limbic activation to cigarette smoking cues independent of nicotine withdrawal: A perfusion fMRI study. Neuropsychopharmacology, 32(11), 2301-2309. doi:10.1038/sj.npp.1301371

Gardner, P. H., McMillan, B., Raynor, D. K., Woolf, E., \& Knapp, P. (2011). The effect of numeracy on the comprehension of information about medicines in users of a patient information website. Patient and Education Counselling, 83(3), 398-403. doi:10.1016/j.pec.2011.05.006

Hall, E. W., Sanchez, T. H., Stein, A. D., Stephenson, R., Zlotorzynska, M., Sineath, R. C., \& Sullivan, P. S. (2017). Use of videos improves informed consent comprehension in web-based surveys among Internet-using men who have sex with men: A randomized controlled trial. Journal of Medical Internet Research, 19(3), e64. doi:10.2196/jmir.6710

Harrison, B. J., Fullana, M. A., Via, E., Soriano-Mas, C., Vervliet, B., Martinez-Zalacain, I., Pujol, J., Davey, C. G., Kircher, T., Straube, B., \& Cardoner, N. (2017). Human ventromedial prefrontal cortex and the positive affective processing of safety signals. Neuroimage, 152, 12-18. doi:10.1016/j.neuroimage. 2017.02.080

Havlicek, M., Roebroeck, A., Friston, K., Gardumi, A., Ivanov, D., \& Uludag, K. (2015). Physiologically informed dynamic causal modeling of fMRI data. Neuroimage, 122, 355-372. doi:10.1016/j.neuroimage.2015.07.078

Hawi, N. S., Samaha, M., \& Griffiths, M. D. (2018). Internet gaming disorder in Lebanon: Relationships with age, sleep habits, and academic achievement. Journal of Behavioral Addictions, 7(1), 70-78. doi:10.1556/2006.7.2018.16

He, Q., Huang, X., Zhang, S., Turel, O., Ma, L., \& Bechara, A. (2019). Dynamic causal modeling of insular, striatal, and prefrontal cortex activities during a food-specific Go/NoGo task. Biological Psychiatry: Cognitive Neuroscience and Neuroimaging, 4(12), 1080-1089. doi:10.1016/j.bpsc.2018. 12.005

Ikemoto, S., Yang, C., \& Tan, A. (2015). Basal ganglia circuit loops, dopamine and motivation: A review and enquiry. Behavioural Brain Research, 290, 17-31. doi:10.1016/j.bbr.2015. 04.018

Kim, S. N., Kim, M., Lee, T. H., Lee, J. Y., Park, S., Park, M., Kim, D. J., Kwon, J. S., \& Choi, J. S. (2018). Increased attentional bias toward visual cues in Internet gaming disorder and obsessive-compulsive disorder: An event-related potential study. Frontiers in Psychiatry, 9, 315. doi:10.3389/fpsyt. 2018.00315

King, D. L., \& Gaming Industry Response Consortium. (2018). Comment on the global gaming industry's statement on ICD11 gaming disorder: A corporate strategy to disregard harm and deflect social responsibility? Addiction, 113(11), 2145-2146. doi:10.1111/add.14388

Knutson, B., Fong, G. W., Adams, C. M., Varner, J. L., \& Hommer, D. (2001). Dissociation of reward anticipation and outcome with event-related fMRI. Neuroreport, 12(17), 3683-3687. doi:10.1097/00001756-200112040-00016

Knutson, B., \& Greer, S. M. (2008). Anticipatory affect: Neural correlates and consequences for choice. Philosophical Transactions of the Royal Society of London, 363(1511), 3771-3786. doi:10.1098/rstb.2008.0155

Ko, C. H., Liu, G. C., Hsiao, S., Yen, J. Y., Yang, M. J., Lin, W. C., Yen, C. F., \& Chen, C. S. (2009). Brain activities associated with gaming urge of online gaming addiction. Journal of Psychiatric Research, 43(7), 739-747. doi:10.1016/j.jpsychires. 2008.09.012

Ko, C. H., Liu, G. C., Yen, J. Y., Yen, C. F., Chen, C. S., \& Lin, W. C. (2013). The brain activations for both cue-induced gaming urge and smoking craving among subjects comorbid with Internet gaming addiction and nicotine dependence. Journal of Psychiatric Research, 47(4), 486-493. doi:10.1016/ j.jpsychires.2012.11.008

Ko, C. H., Liu, T. L., Wang, P. W., Chen, C. S., Yen, C. F., \& Yen, J. Y. (2014). The exacerbation of depression, hostility, and social anxiety in the course of Internet addiction among adolescents: A prospective study. Comprehensive Psychiatry, 55(6), 1377-1384. doi:10.1016/j.comppsych.2014.05.003

Ko, C. H., Wang, P. W., Liu, T. L., Yen, C. F., Chen, C. S., \& Yen, J. Y. (2015). Bidirectional associations between family factors and Internet addiction among adolescents in a prospective investigation. Psychiatry and Clinical Neurosciences, 69(4), 192-200. doi:10.1111/pcn.12204 
Kober, H., Lacadie, C. M., Wexler, B. E., Malison, R. T., Sinha, R., \& Potenza, M. N. (2016). Brain activity during cocaine craving and gambling urges: An fMRI study. Neuropsychopharmacology, 41(2), 628-637. doi:10.1038/npp.2015.193

Kober, H., Mende-Siedlecki, P., Kross, E. F., Weber, J., Mischel, W., Hart, C. L., \& Ochsner, K. N. (2010). Prefrontalstriatal pathway underlies cognitive regulation of craving. Proceedings of the National Academy of Sciences of the United States of America, 107(33), 14811-14816. doi:10.1073/ pnas. 1007779107

Kosten, T. R., Scanley, B. E., Tucker, K. A., Oliveto, A., Prince, C., Sinha, R., Potenza, M. N., Skudlarski, P., \& Wexler, B. E. (2005). Cue-induced brain activity changes and relapse in cocaine-dependent patients. Neuropsychopharmacology, 31(3), 644-650. doi:10.1038/sj.npp.1300851

Lau, J. T. F., Wu, A. M. S., Gross, D. L., Cheng, K. M., \& Lau, M. M. G. (2017). Is Internet addiction transitory or persistent? Incidence and prospective predictors of remission of Internet addiction among Chinese secondary school students. Addictive Behaviors, 74, 55-62. doi:10.1016/j.addbeh.2017.05.034

Lecrubier, Y., Sheehan, D. V., Weiller, E., Amorim, P., Bonora, I., Sheehan, K. H., Janavs, J., \& Dunbar, G. C. (1997). The Mini International Neuropsychiatric Interview (MINI). A short diagnostic structured interview: Reliability and validity according to the CIDI. European Psychiatry, 12(5), 224-231. doi:10.1016/S0924-9338(97)83296-8

Leeman, R. F., \& Potenza, M. N. (2012). Similarities and differences between pathological gambling and substance use disorders: A focus on impulsivity and compulsivity. Psychopharmacology (Berlin), 219(2), 469-490. doi:10.1007/s00213011-2550-7

Li, W., Mai, X., \& Liu, C. (2014). The default mode network and social understanding of others: What do brain connectivity studies tell us. Frontiers in Human Neuroscience, 8, 74. doi:10.3389/fnhum.2014.00074

Liu, L., Yip, S. W., Zhang, J. T., Wang, L. J., Shen, Z. J., Liu, B., Ma, S. S., Yao, Y. W., \& Fang, X. Y. (2017). Activation of the ventral and dorsal striatum during cue reactivity in Internet gaming disorder. Addiction Biology, 22(3), 791-801. doi:10.1111/adb.12338

Ma, S. S., Worhunsky, P. D., Xu, J. S., Yip, S. W., Zhou, N., Zhang, J. T., Liu, L., Wang, L. J., Liu, B., Yao, Y. W., Zhang, S., \& Fang, X. Y. (2019). Alterations in functional networks during cue-reactivity in Internet gaming disorder. Journal of Behavioral Addictions, 8(2), 277-287. doi:10.1556/ 2006.8.2019.25

Myrick, H., Anton, R. F., Li, X., Henderson, S., Drobes, D., Voronin, K., \& George, M. S. (2004). Differential brain activity in alcoholics and social drinkers to alcohol cues: Relationship to craving. Neuropsychopharmacology, 29(2), 393-402. doi:10.1038/sj.npp.1300295

Nuyens, F., Deleuze, J., Maurage, P., Griffiths, M. D., Kuss, D. J., \& Billieux, J. (2016). Impulsivity in multiplayer online battle arena gamers: Preliminary results on experimental and self-report measures. Journal of Behavioral Addictions, 5(2), 351-356. doi:10.1556/2006.5.2016.028

Pawlikowski, M., \& Brand, M. (2011). Excessive Internet gaming and decision making: Do excessive World of Warcraft players have problems in decision making under risky conditions? Psychiatry Research, 188(3), 428-433. doi:10.1016/ j.psychres.2011.05.017
Petry, N. M., Rehbein, F., Gentile, D. A., Lemmens, J. S., Rumpf, H. J., Mößle, T., Bischof, G., Tao, R., Fung, D. S., Borges, G., Auriacombe, M., González Ibáñez, A., Tam, P., \& O’Brien, C. P. (2014). An international consensus for assessing Internet gaming disorder using the new DSM-5 approach. Addiction, 109(9), 1399-1406. doi:10.1111/add.12457

Petry, N. M., Rehbein, F., Ko, C. H., \& O’Brien, C. P. (2015). Internet gaming disorder in the DSM-5. Current Psychiatry Reports, 17(9), 72. doi:10.1007/s11920-015-0610-0

Potenza, M. N., Balodis, I. M., Franco, C. A., Bullock, S., Xu, J., Chung, T., \& Grant, J. E. (2013). Neurobiological considerations in understanding behavioral treatments for pathological gambling. Psychology of Addictive Behaviors, 27(2), 380-392. doi:10.1037/a0032389

Potenza, M. N., Steinberg, M. A., Skudlarski, P., Fulbright, R. K., Lacadie, C. M., Wilber, M. K., Rounsaville, B. J., \& Gore, J. C. (2003). Gambling urges in pathological gambling: A functional magnetic resonance imaging study. Archives of General Psychiatry, 60(8), 828-836. doi:10.1001/archpsyc.60.8.828

Qi, X., Yang, Y., Dai, S., Gao, P., Du, X., Zhang, Y., Du, G., Li, X., \& Zhang, Q. (2016). Effects of outcome on the covariance between risk level and brain activity in adolescents with Internet gaming disorder. NeuroImage: Clinical, 12, 845-851. doi:10.1016/j.nicl.2016.10.024

Rolls, E. T. (2000). The orbitofrontal cortex and reward. Cerebral Cortex, 10(3), 284-294. doi:10.1093/cercor/10.3.284

Rumpf, H. J., Achab, S., Billieux, J., Bowden-Jones, H., Carragher, N., Demetrovics, Z., Higuchi, S., King, D. L., Mann, K., Potenza, M., Saunders, J. B., Abbott, M., Ambekar, A., Aricak, O. T., Assanangkornchai, S., Bahar, N., Borges, G., Brand, M., Chan, E. M., Chung, T., Derevensky, J., Kashef, A. E., Farrell, M., Fineberg, N. A., Gandin, C., Gentile, D. A., Griffiths, M. D., Goudriaan, A. E., Grall-Bronnec, M., Hao, W., Hodgins, D. C., Ip, P., Király, O., Lee, H. K., Kuss, D., Lemmens, J. S., Long, J., Lopez-Fernandez, O., Mihara, S., Petry, N. M., Pontes, H. M., Rahimi-Movaghar, A., Rehbein, F., Rehm, J., Scafato, E., Sharma, M., Spritzer, D., Stein, D. J., Tam, P., Weinstein, A., Wittchen, H. U., Wölfling, K., Zullino, D., \& Poznyak, V. (2018). Including gaming disorder in the ICD-11: The need to do so from a clinical and public health perspective. Journal of Behavioral Addictions, 7(3), 556-561. doi:10.1556/2006.7.2018.59

Saunders, J. B., Hao, W., Long, J., King, D. L., Mann, K., FauthBuhler, M., Rumpf, H. J., Bowden-Jones, H., RahimiMovaghar, A., Chung, T., Chan, E., Bahar, N., Achab, S., Lee, H. K., Potenza, M., Petry, N., Spritzer, D., Ambekar, A., Derevensky, J., Griffiths, M. D., Pontes, H. M., Kuss, D., Higuchi, S., Mihara, S., Assangangkornchai, S., Sharma, M., Kashef, A. E., Ip, P., Farrell, M., Scafato, E., Carragher, N., \& Poznyak, V. (2017). Gaming disorder: Its delineation as an important condition for diagnosis, management, and prevention. Journal of Behavioral Addictions, 6(3), 271-279. doi:10.1556/2006.6.2017.039

Sayette, M. A. (2016). The role of craving in substance use disorders: Theoretical and methodological issues. Annual Review of Clinical Psychology, 12(1), 407-433. doi:10.1146/ annurev-clinpsy-021815-093351

Sayette, M. A., Schooler, J. W., \& Reichle, E. D. (2010). Out for a smoke: The impact of cigarette craving on zoning out during reading. Psychological Science, 21(1), 26-30. doi:10.1177/ 0956797609354059 
Sinha, R., \& Li, C. S. (2007). Imaging stress- and cue-induced drug and alcohol craving: Association with relapse and clinical implications. Drug and Alcohol Review, 26(1), 25-31. doi:10.1080/09595230601036960

Slutske, W. S. (2006). Natural recovery and treatment-seeking in pathological gambling: Results of two U. S. national surveys. The American Journal of Psychiatry, 163(2), 297-302. doi:10.1176/appi.ajp.163.2.297

Slutske, W. S., Piasecki, T. M., Blaszczynski, A., \& Martin, N. G. (2010). Pathological gambling recovery in the absence of abstinence. Addiction, 105(12), 2169-2175. doi:10.1111/ j.1360-0443.2010.03080.x

Stephan, K. E., Penny, W. D., Moran, R. J., den Ouden, H. E. M., Daunizeau, J., \& Friston, K. J. (2010). Ten simple rules for dynamic causal modeling. Neuroimage, 49(4), 3099-3109. doi:10.1016/j.neuroimage.2009.11.015

Sun, Y., Ying, H., Seetohul, R. M., Xuemei, W., Ya, Z., Qian, L., Guoqing, X., \& Ye, S. (2012). Brain fMRI study of crave induced by cue pictures in online game addicts (male adolescents). Behavioural Brain Research, 233(2), 563-576. doi:10. 1016/j.bbr.2012.05.005

Tanabe, J., Thompson, L., Claus, E., Dalwani, M., Hutchison, K., \& Banich, M. T. (2007). Prefrontal cortex activity is reduced in gambling and nongambling substance users during decisionmaking. Human Brain Mapping, 28(12), 1276-1286. doi:10.1002/hbm.20344

Tiffany, S. T. (1990). A cognitive model of drug urges and druguse behavior: Role of automatic and nonautomatic processes. Neuropsychology Review, 97(2), 147-168. doi:10.1037/0033295x.97.2.147

Tobler, P. N., Preller, K. H., Campbell-Meiklejohn, D. K., Kirschner, M., Kraehenmann, R., Stampfli, P., Herdener, M., Seifritz, E., \& Quednow, B. B. (2016). Shared neural basis of social and non-social reward deficits in chronic cocaine users. Social Cognitive and Affective Neuroscience, 11(6), 1017-1025. doi:10.1093/scan/nsw030

Wang, Y., Wu, L., Wang, L., Zhang, Y., Du, X., \& Dong, G. (2017). Impaired decision-making and impulse control in Internet gaming addicts: Evidence from the comparison with recreational Internet game users. Addiction Biology, 22(6), 1610-1621. doi:10.1111/adb.12458

Wang, Y., Wu, L., Zhou, H., Lin, X., Zhang, Y., Du, X., \& Dong, G. (2017). Impaired executive control and reward circuit in Internet gaming addicts under a delay discounting task: Independent component analysis. European Archives of Psychiatry and Clinical Neuroscience, 267(3), 245-255. doi:10.1007/ s00406-016-0721-6

Wexler, B. E., Gottschalk, C. H., Fulbright, R. K., Prohovnik, I., Lacadie, C. M., Rounsaville, B. J., \& Gore, J. C. (2001). Functional magnetic resonance imaging of cocaine craving. The American Journal of Psychiatry, 158(1), 86-95. doi:10.1176/appi.ajp.158.1.86

Worhunsky, P. D., Malison, R. T., Rogers, R. D., \& Potenza, M. N. (2014). Altered neural correlates of reward and loss processing during simulated slot-machine fMRI in pathological gambling and cocaine dependence. Drug and Alcohol Dependence, 145, 77-86. doi:10.1016/j.drugalcdep.2014.09.013

Wrase, J., Grüsser, S. M., Klein, S., Diener, C., Hermann, D., Flor, H., Mann, K., Braus, D. F., \& Heinz, A. (2002). Development of alcohol-associated cues and cue-induced brain activation in alcoholics. European Psychiatry, 17(5), 287-291. doi:10.1016/ S0924-9338(02)00676-4

Yang, L. Z., Shi, B., Li, H., Zhang, W., Liu, Y., Wang, H. Z., Lv, W., Ji, X., Hudak, J., Zhou, Y., Fallgatter, A. J., \& Zhang, X. C. (2017). Electrical stimulation reduces smokers' craving by modulating the coupling between dorsal lateral prefrontal cortex and parahippocampal gyrus. Social Cognitive and Affective Neuroscience, 12(8), 1296-1302. doi:10.1093/scan/nsx055

Yip, S. W., Worhunsky, P. D., Xu, J., Morie, K. P., Constable, R. T., Malison, R. T., Carroll, K. M., \& Potenza, M. N. (2018). Gray-matter relationships to diagnostic and transdiagnostic features of drug and behavioral addictions. Addiction Biology, 23(1), 394-402. doi:10.1111/adb.12492

Young, K. (2009). Internet addiction: Diagnosis and treatment considerations. Journal of Contemporary Psychotherapy, 39(4), 241-246. doi:10.1007/s10879-009-9120-x

Young, K. S., \& Brand, M. (2017). Merging theoretical models and therapy approaches in the context of Internet gaming disorder: A personal perspective. Frontiers in Psychology, 8, 1853. doi:10.3389/fpsyg.2017.01853

Zhang, J. T., Yao, Y. W., Potenza, M. N., Xia, C. C., Lan, J., Liu, L., Wang, L. J., Liu, B., Ma, S. S., \& Fang, X. Y. (2016a). Altered resting-state neural activity and changes following a craving behavioral intervention for Internet gaming disorder. Scientific Reports, 6(1), 28109. doi:10.1038/srep28109

Zhang, J. T., Yao, Y. W., Potenza, M. N., Xia, C. C., Lan, J., Liu, L., Wang, L. J., Liu, B., Ma, S. S., \& Fang, X. Y. (2016b). Effects of craving behavioral intervention on neural substrates of cue-induced craving in Internet gaming disorder. NeuroImage: Clinical, 12, 591-599. doi:10.1016/j.nicl.2016.09.004 